\title{
Dementia in Latin America
}

\section{Assessing the present and envisioning the future}

Mario A. Parra, MD, PhD, Sandra Baez, PhD, Ricardo Allegri, MD, PhD, Ricardo Nitrini, PhD, Francisco Lopera, MD, PhD, Andrea Slachevsky, MD, PhD, Nilton Custodio, MD, PhD, David Lira, PhD, Olivier Piguet, PhD, Fiona Kumfor, PhD, David Huepe, PhD, Patricia Cogram, PhD, Thomas Bak, PhD, Facundo Manes, MD, PhD, and Agustin Ibanez, PhD

Neurology ${ }^{\circledR}$ 2018;90:222-231. doi:10.1212/WNL.0000000000004897

\section{Correspondence}

Dr. Ibanez

aibanez@ineco.org.ar

\begin{abstract}
The demographic structure of Latin American countries (LAC) is fast approaching that of developing countries, and the predicted prevalence of dementia in the former already exceeds the latter. Dementia has been declared a global challenge, yet regions around the world show differences in both the nature and magnitude of such a challenge. This article provides evidence and insights on barriers which, if overcome, would enable the harmonization of strategies to tackle the dementia challenge in LAC. First, we analyze the lack of available epidemiologic data, the need for standardizing clinical practice and improving physician training, and the existing barriers regarding resources, culture, and stigmas. We discuss how these are preventing timely care and research. Regarding specific health actions, most LAC have minimal mental health facilities and do not have specific mental health policies or budgets specific to dementia. In addition, local regulations may need to consider the regional context when developing treatment and prevention strategies. The support needed nationally and internationally to enable a smooth and timely transition of LAC to a position that integrates global strategies is highlighted. We focus on shared issues of poverty, cultural barriers, and socioeconomic vulnerability. We identify avenues for collaboration aimed to study unique populations, improve valid assessment methods, and generate opportunities for translational research, thus establishing a regional network. The issues identified here point to future specific actions aimed at tackling the dementia challenge in LAC.
\end{abstract}

From the School of Life Sciences (M.A.P.), Psychology, University Heriot-Watt; Human Cognitive Neuroscience (M.A.P.), Psychology, Edinburgh University; Alzheimer's Scotland Dementia Research Centre and Scottish Dementia Clinical Research Network (M.A.P.), Edinburgh; Centre for Cognitive Ageing and Cognitive Epidemiology (M.A.P., T.B.) and Department of Psychology, School of Philosophy, Psychology and Language Sciences (P.C., T.B.), University of Edinburgh, UK; Universidad Autónoma del Caribe (M.A.P., A.I.), Barranquilla, Colombia; Consejo Nacional de Investigaciones Científicas y Técnicas (CONICET) (S.B., F.M., A.I.); Institute of Translational and Cognitive Neuroscience (INCYT) (S.B., F.M., A.I.), INECO Foundation, Favaloro University, Buenos Aires, Argentina; Departamento de Psicología (S.B.) Universidad de los Andes, Bogotá, Colombia; Department of Cognitive Neurology and Neuropsychology (R.A.), Instituto de Investigaciones Neurológicas "Raúl Carrea" (FLENI) (R.A.), Buenos Aires, Argentina; Universidad de la Costa (CUC) (R.A.), Barranquilla, Colombia; Department of Neurology (R.N.), University of São Paulo Medical School, Brazil; Group of Neuroscience (F.L.), University of Antioquia, Medellín, Colombia; Geroscience Center for Brain Health and Metabolism (A.S.); Physiopathology Department, ICBM, and East Neuroscience Department, Faculty of Medicine (A.S.), and Center for Advanced Research in Education (CIAE) (A.S.), University of Chile; Cognitive Neurology and Dementia, Neurology Department (A.S.), Hospital del Salvador; Neurology Department, Clínica Alemana (A.S.), Santiago, Chile; Research Unit, Peruvian Institute of Neurosciences (N.C., D.L.) and Unit Cognitive Impairment and Dementia Prevention (N.C., D.L.), Lima, Peru; Brain and Mind Centre \& School of Psychology (O.P., F.K.), Faculty of Science, University of Sydney; ARC Centre of Excellence in Cognition and its Disorders (O.P., F.K., F.M., A.I.), Sydney, Australia; Fraunhofer Chile (O.P., P.C.), Santiago; and Center for Social and Cognitive Neuroscience (CSCN), School of Psychology (D.H., A.I.), Universidad Adolfo Ibáñez, Santiago, Chile.

Go to Neurology.org/N for full disclosures. Funding information and disclosures deemed relevant by the authors, if any, are provided at the end of the article. 


\section{Glossary}

$\mathrm{AD}=$ Alzheimer disease $\mathbf{A D I}=$ Alzheimer's Disease International; $\mathbf{A I}=$ acetylcholinesterase inhibitors; HIC $=$ high-income countries; LAC = Latin American countries; LIC = low-income countries; UMIC = upper-middle-income countries.

The call to fight dementia has gone global. ${ }^{1}$ However, the strategies, procedures, and tools to address this urgent issue have not, with important barriers persisting in Latin American countries (LAC) (see appendix e-1, S1, for a definition of LAC, links.lww.com/WNL/A97). The demographic structure of LAC is fast approaching that of developing countries ${ }^{2}$ and the predicted prevalence of dementia in the former already outreaches that in the latter. ${ }^{3}$ Although high variability among LAC exists, demographic transition in this region is happening fast. In addition, fertility rates and their relative decline have been uneven across LAC (appendix e-1, S3). Yet understanding of the factors relevant to dementia is currently limited, ${ }^{4}$ and a high proportion of people with dementia in the region lack basic support. $^{5}$

\section{The goal of this work}

In this Perspective, we discuss the clinical and research priorities necessary to enable harmonization of strategies to tackle the dementia challenge in LAC. Regarding clinical priorities, we discuss the current diagnostic procedures (table 1), the need for improving physician training, and factors affecting timely diagnosis and care. We also consider specific issues regarding mental health facilities and policies. Regarding research priorities, we highlight the lack of epidemiologic data and the need for standardized diagnostic procedures. We also discuss the use of biomarkers and the context of clinical trials in LAC. Finally, we propose avenues for collaborations including dissemination forums, research with unique populations, and opportunities for a regional network for translational research. A consensus is needed to enter the global dementia scenario with an appealing proposal that focuses on the harmonization of actions across LAC in a way that captures global dementia strategies.

The dementia challenge for LAC was recently highlighted in the World Congress of Neurology meeting held in Santiago, Chile. ${ }^{2}$ A group of experts from various LAC came together to discuss concerns regarding barriers and challenges in clinical research practice (appendix e-1, S2, links.lww.com/WNL/A97). Four topics were addressed and are discussed here: (1) timely diagnosis, (2) therapeutic approaches, (3) social and health support after the diagnosis, and (4) potential avenues for collaboration toward unmet needs. It was acknowledged by consensus that such topics could trigger immediate actions (table 2).

\section{Timely diagnosis}

Recent dementia recommendations stress the importance of systematic and exhaustive clinical and cognitive investigations, as well as biomarker approaches, to support both the timely diagnosis of Alzheimer disease $(\mathrm{AD})^{6}$ and prevention initiatives. ${ }^{7,8}$ Whether such recommendations can be harmonized across the developed and developing world is unclear at present. Moreover, the potential benefit of timely diagnosis and the clinical utility of biomarkers has been questioned both at the societal and individual level., ${ }^{9,10}$ Although the use of biomarkers as diagnostic criteria offers value in research settings, concerns about the premature use of biomarkers in clinical settings have been raised. Even if biomarkers are proven to be accurate for diagnosis, the associated patient benefit should be considered, particularly in light of the cost of proposed biomarkers and the necessary access to high-level equipment that is currently unavailable in most LAC. ${ }^{11}$ The utility of biomarkers is further questionable in low-income countries (LIC), where the priority should be timely diagnosis using affordable neuropsychological and clinical assessments, and appropriate patient care. Thus, the potential utility of biomarkers may be predominantly in high-income countries (HIC) and to a lesser degree in upper-middle-income countries (UMIC). Thus, the use of biomarkers may represent a step toward better future assessment predominantly in $\mathrm{HIC},{ }^{12}$ while care and clinical assessment should be a priority in LIC and UMIC (see below). There is a stringent limit to the budget available for research in LIC and UMIC and the use of biomarkers would likely imply a tradeoff between quality of measurement and other desirable features of research such as geographic, socioeconomic, and racial diversity of sample participation as well as sample size, response rates, and cost, to mention a few.

Challenges for LAC relevant to this call include the current epidemiologic landscape, training of health care practitioners, procedures followed to make a diagnosis, and factors affecting timely diagnosis.

\section{Current epidemiologic landscape}

From 2015 to 2050, the number of people with dementia in LAC is predicted to increase 4-fold. ${ }^{3,13-15}$ By 2020, 89.28 million people with dementia will live in LMIC (in LAC: Bolivia, el Salvador, Guatemala, Honduras, Nicaragua, Paraguay), relative to the 42.18 million living in HIC. In addition, UMIC, such as Argentina, Brazil, Chile, Costa Rica, Cuba, Colombia, Dominican Republic, Ecuador, Mexico, Peru, Uruguay, and Venezuela, will experience the greatest 
Table 1 Diagnostic procedures followed by experts from the participating countries

\begin{tabular}{|c|c|c|c|c|c|c|c|}
\hline \multirow[b]{2}{*}{ LAC } & \multirow[b]{2}{*}{$\begin{array}{l}\text { Diagnostic workup: Steps to achieve } \\
\text { a diagnosis }\end{array}$} & \multirow[b]{2}{*}{$\begin{array}{l}\text { Cognitive screening tests and } \\
\text { neuropsychiatric scales }\end{array}$} & \multicolumn{5}{|c|}{ Biomarkers } \\
\hline & & & CSF & $\begin{array}{l}\text { Amyloid/ } \\
\text { tau-PET }\end{array}$ & $\begin{array}{l}\text { FDG- } \\
\text { PET }\end{array}$ & MRI & EEG \\
\hline Argentina & $\begin{array}{l}\text { The diagnosis is usually made by the GP } \\
\text { relying on the clinical history, laboratory tests, } \\
\text { and a CT scan. The GP rarely requests a full } \\
\text { neuropsychological assessment. }\end{array}$ & MMSE; ACE-R; IFS & $Y e s^{a, c}$ & Yes $^{a, c}$ & $Y_{e s}{ }^{a, c}$ & Yes $^{a}$ & Yes $^{\mathrm{b}}$ \\
\hline Brazil & $\begin{array}{l}\text { Diagnosis is usually based on information of } \\
\text { cognitive decline provided by informants, } \\
\text { clinical examination, cognitive screening } \\
\text { tests, blood tests, and CT or MRI. }\end{array}$ & $\begin{array}{l}\text { MMSE; MoCA; Brief Cognitive Screening } \\
\text { Battery }\end{array}$ & $\mathrm{Yes}^{\mathrm{a}, \mathrm{c}}$ & $Y_{e s}^{a, c}$ & Yes $^{\mathrm{b}}$ & Yes $^{\mathrm{a}}$ & No \\
\hline Caribbean & $\begin{array}{l}\text { The criterion validity of } 10 / 66 \text { diagnosis was } \\
\text { superior to that of DSM-IV. }{ }^{16}\end{array}$ & $\begin{array}{l}\text { Community Screening Instrument for } \\
\text { Dementia, CERAD; cognitive test; } \\
\text { Geriatric Mental State; and structured } \\
\text { neurologic examination }\end{array}$ & $Y_{e s}^{a, c}$ & Yes $^{a, c}$ & Yes $^{\mathrm{b}}$ & Yes $^{a}$ & No \\
\hline Chile & $\begin{array}{l}\text { At the primary health level, people }>65 \text { years } \\
\text { undergo medical and functional examination } \\
\text { (EMPAN and EFAM). They can be either } \\
\text { referred to memory stimulation groups or to } \\
\text { secondary health care. This pathway is } \\
\text { available to approximately } 40.3 \% \text { of the } \\
\text { population at risk. At the secondary level, } \\
\text { diagnosis is based on neuropsychological } \\
\text { assessment, laboratory tests, and CT or MRI } \\
\text { scans. }\end{array}$ & $\begin{array}{l}\text { EFAM includes an abbreviated version } \\
\text { of the MMSE, the Pfeffer Functional } \\
\text { Assessment Scale, and the evaluation } \\
\text { of the risk of falls; the Chilean version } \\
\text { of the ACE-R; The T-ADLQ; AD-8-Ch; } \\
\text { Picture and Verbal Version of the Free } \\
\text { and Cued Selective Reminding Test }\end{array}$ & No & No & $Y_{e s}{ }^{b}$ & Yes $^{\mathrm{a}}$ & No \\
\hline Colombia & $\begin{array}{l}\text { The diagnosis relies on the clinical history } \\
\text { gathered from patient and family members, } \\
\text { neuropsychological assessment, brain } \\
\text { neuroimaging, and laboratory tests. Some } \\
\text { groups have implemented a genetic interview } \\
\text { (i.e., genealogy). }\end{array}$ & $\begin{array}{l}\text { CERAD neuropsychological } \\
\text { battery, MoCA, and IFS }\end{array}$ & Yes $^{\mathrm{b}}$ & Yes $^{\mathrm{b}}$ & Yes $^{\mathrm{b}}$ & Yes $^{a}$ & $Y_{e s}{ }^{b}$ \\
\hline Cuba & $\begin{array}{l}\text { The criterion validity of the } 10 / 66 \text { diagnosis } \\
\text { was superior to that of DSM-IV. }{ }^{16}\end{array}$ & $\begin{array}{l}\text { Community Screening Instrument for } \\
\text { Dementia; CERAD; cognitive test; } \\
\text { Geriatric Mental State; and structured } \\
\text { neurologic examination }\end{array}$ & $Y_{e s}^{a, c}$ & Yes $^{a, c}$ & Yes $^{\mathrm{b}}$ & Yes $^{a}$ & No \\
\hline Mexico & $\begin{array}{l}\text { The criterion validity of the } 10 / 66 \text { diagnosis } \\
\text { was superior to that of DSM-IV. }{ }^{16}\end{array}$ & $\begin{array}{l}\text { Community Screening Instrument for } \\
\text { Dementia; CERAD; cognitive test; } \\
\text { Geriatric Mental State; and structured } \\
\text { neurologic examination }\end{array}$ & $Y_{e s}^{a, c}$ & $Y_{e s}^{a, c}$ & $Y_{e s}^{b}$ & Yes $^{a}$ & No \\
\hline Peru & $\begin{array}{l}\text { Three successive steps: screening, diagnosis, } \\
\text { and classification (i.e., dementia subtypes). All } \\
\text { patients with cognitive impairment identified } \\
\text { by the screening tests carry out the } \\
\text { evaluations proposed in steps } 2 \text { and } 3 \text {. } \\
\text { Diagnosis is based on cognitive screening } \\
\text { tests, laboratory tests, and CT or MRI scans. }\end{array}$ & $\begin{array}{l}\text { Screening phase: MMSE; the Clock } \\
\text { Drawing Test, Mano version; the } \\
\text { Pfeffer Functional Activities } \\
\text { Questionnaire; the Memory Alteration } \\
\text { Test; diagnosis phase: the Beck } \\
\text { Depression Index; ACE }\end{array}$ & No & No & Yes & Yes $^{a}$ & No \\
\hline
\end{tabular}

Abbreviations: $A C E-R=$ Addenbrooke's Cognitive Examination-revised; CERAD = Consortium to Establish a Registry for Alzheimer's Disease; DSM-IV = Diagnostic and Statistical Manual of Mental Disorders, 4th edition; GP = general practitioner; IFS = INECO Frontal Screening; LAC = Latin American countries; MMSE = Mini-Mental State Examination; MoCA = Montreal Cognitive Assessment.

In several LAC (e.g., Bolivia, Costa Rica, el Salvador, Panama, Paraguay, Uruguay), we were unable to find sufficient evidence to include these countries in the table. a Employed for clinical purposes.

${ }^{\mathrm{b}}$ Only for research purposes.

' Restricted to a few health institutions.

dementia impact. ${ }^{16}$ As is the case globally, the expected increase in dementia in LAC is partly due to the aging population. ${ }^{17,18} \mathrm{~A}$ combination of unsuitable diagnostic procedures and low awareness has prevented accurate estimates of dementia prevalence in LAC. ${ }^{19}$ The WHO reported a dementia prevalence of $5.5 \%-7 \%$ with a standardized prevalence of $8.5 \%$, although several LAC are underrepresented in these statistics, ${ }^{16}$ and dementia prevalence may be underestimated. ${ }^{20}$ Most reports rely on a limited number of studies, which provide only a partial picture of the problem in LAC. ${ }^{4}$ Thus, more rigorous epidemiologic studies are required ${ }^{21}$ (table 3 ).

The Alzheimer's Disease International (ADI) report ${ }^{14}$ included figures from Cuba, Dominican Republic, Jamaica, Peru, Venezuela, Mexico, Chile, and Brazil (14 publications). Ethnic minorities in the United States reported prevalence of dementia in Caribbean Hispanic Americans (12.2\%) higher than in Mexican Americans, Japanese Americans, and nonLatino white populations. ${ }^{22}$ In fact, ADI reported the highest 
Table 2 Actions toward a unified working agenda for Latin American countries (LAC)

\begin{tabular}{lll}
\hline Levels of action & Issues & Suggested strategies \\
\hline $\begin{array}{l}\text { Dissemination and } \\
\text { promoting a positive } \\
\text { dementia culture }\end{array}$ & $\begin{array}{l}\text { Lack of motivation and confidence, } \\
\text { language barriers, or a combination of } \\
\text { these factors prevent timely and } \\
\text { accurate reporting of epidemiologic } \\
\text { data. }\end{array}$ & $\begin{array}{l}\text { To establish a partnership with world leading organizations in the field. Support will be } \\
\text { sought toward effective strategies for dissemination and education of relevant } \\
\text { stakeholders (e.g., National Plan for Dementia in Chile). }\end{array}$ \\
\end{tabular}

New initiatives can be launched by higher education institutions of LAC to incentivize and promote dissemination of scientific research in international peer-reviewed journals.

To generate a regional dementia strategy for LAC addressed to heads of government and international agencies to raise awareness about specific factors delaying the diagnosis of dementia and to make recommendations about feasible and affordable strategies to overcome existing barriers including resources, culture, and stigmas.

To raise awareness through such a strategy on regional factors limiting participation of LAC in worldwide dementia prevention initiatives (local policies, lack of registries). To highlight the importance of setting up national registries and brain bank facilities and linking them across LAC.

To promote a participatory culture in dementia research, which can be formed via community groups, general practitioners, community nurses, or national media.

\begin{tabular}{ll}
\hline Health $\quad$ Lack of training & $\begin{array}{l}\text { To develop a regional training program for dementia. Such a program should address } \\
\text { the needs of different participants such as carers, nurses, social workers, general } \\
\text { practitioners, and other health professionals. Recommendations are made to } \\
\text { incorporate dementia training in the curriculum for undergraduate and postgraduate } \\
\text { programs. }\end{array}$
\end{tabular}

To coordinate a pilot study to assess feasibility of telemedicine platforms to provide support on issues prediagnosis and postdiagnosis. To this aim, LAC can rely on colleagues from Universidad Central de Venezuela to explore avenues of collaboration.

\begin{tabular}{lll}
\hline Political & Government and international support & $\begin{array}{l}\text { A systematic pursuit of support from national and international agencies. This will } \\
\text { include drafting an agenda for heads of governments aimed at raising awareness } \\
\text { among politicians of the status quo in the field of dementia in LAC. }\end{array}$ \\
\hline Scientific & $\begin{array}{l}\text { Promote local exchange to maximize } \\
\text { resource utilization and access }\end{array}$ & $\begin{array}{l}\text { The agenda will include (1) a LAC Congress on Dementia with regional journals } \\
\text { providing the dissemination forum; (2) the development of online platforms to manage } \\
\text { registries of special populations, share data across LAC, and facilitate project } \\
\text { management as well as training; and (3) consolidation of a regional network for } \\
\text { translational neuroscience. }\end{array}$ \\
\hline & $\begin{array}{l}\text { More regional discussion is needed among experts in the field to address issues such as } \\
\text { feasibility for LAC to adhere to international guidelines (e.g., table 1) or to develop more } \\
\text { specific regional guidelines. }\end{array}$ \\
\hline $\begin{array}{l}\text { Translation and } \\
\text { implementation }\end{array}$ & $\begin{array}{l}\text { Capitalizing on existing infrastructures } \\
\text { and promoting interdisciplinary work }\end{array}$ & $\begin{array}{l}\text { Establishment of a regional network for translational research and improved } \\
\text { assessment. This will include the implementation of IT platforms to share resources } \\
\text { such as access to regional brain banks, animal models, telecare infrastructure, } \\
\text { postdiagnosis support, training, and intervention programs. }\end{array}$
\end{tabular}

global prevalence of dementia in LAC (8.4\%) after North Africa/Middle East $(8.7 \%)$ in people $>60$ years. ${ }^{14}$ Variability of dementia prevalence rates across LAC, however, is large (ranging from $2 \%$ in Brazil $^{23}$ to $13.7 \%$ in Venezuela, ${ }^{24}$ but this has also been reported in some European countries ${ }^{25}$ ). It has been suggested that such variability may result from differences in methodologic procedures across studies (e.g., diagnostic criteria). Nevertheless, the crude estimated prevalence of dementia in LAC in people $>60$ years (6.54\%) exceeds international prevalence $(5.2 \%),{ }^{16}$ demonstrating the challenge ahead for LAC (table 3 ).

In countries such as Cuba, Dominican Republic, Mexico, and Peru, dementia represents the largest contribution to disability. ${ }^{26}$ The Global Burden of Disease Study (2010) reported that dementia is also one of the key determinants of disability and mortality in older people. ${ }^{5}$ In some LAC, dementia leads to an increase in time disabled by over $200 \%$, and the number of deaths due to dementia has increased by $526 \%$. Moreover, higher rates of deaths among people with dementia in hospital settings are observed in some $\mathrm{LAC}^{27}$ : Cuba 41.4\%; Dominican Republic 29.1\%; Peru (urban) 31.0\%; Peru (rural) 83.3\%; Mexico $31.3 \%$. Notably, hospitalization is one of the main health care cost factors in dementia.

\section{Health care practitioners responsible for the diagnosis of dementia}

The diagnosis of dementia in LAC is usually made by a neurologist, psychiatrist, or gerontologist, or on rare occasions, by a general practitioner. ${ }^{28}$ 
Table 3 Epidemiologic studies in Latin American countries (LAC)

\begin{tabular}{|c|c|c|c|c|c|}
\hline \multirow[b]{2}{*}{ Country } & \multirow[b]{2}{*}{ Study } & \multirow{2}{*}{$\begin{array}{l}\text { Diagnostic } \\
\text { criteria }\end{array}$} & \multirow[b]{2}{*}{ Method, n/sampling/age } & \multicolumn{2}{|c|}{ Prevalence } \\
\hline & & & & Crude & Stand \\
\hline Argentina & Bartoloni et al., $2014^{\mathrm{e} 1}$ & DSM-IV & $\begin{array}{l}1,795 / \text { Door-to door } \\
\text { population-based survey/ } \\
\geq 60\end{array}$ & 8.3 & \\
\hline \multirow[t]{2}{*}{ Brazil } & Herrera Jr et al., $2002^{\mathrm{e} 2}$ & DSM-IV & 1,656/Random/ $\geq 65$ & 7.1 & 7.1 \\
\hline & Ramos-Cerqueira et al., $2005^{\mathrm{e} 3}$ & DSM-IV & $2,222 / O p p o r t u n i s t i c / \geq 65$ & 2.0 & \\
\hline \multirow[t]{2}{*}{ Chile } & Albala et al., 1997, reported by Nitrini et al., $2009^{\mathrm{e} 4}$ & $\begin{array}{l}\text { DSM-III-R and ICD- } \\
10\end{array}$ & 2,213/Random/ $\geq 65$ & 4.4 & 4.1 \\
\hline & Fuentes et al., 2014 ${ }^{\mathrm{e} 5}$ & $\begin{array}{l}\text { National Survey of } \\
\text { Dependency }\end{array}$ & $4,860 /$ Rural and urban/ $\geq 60$ & 7.0 & \\
\hline Colombia & Diaz Cabezas et al., $2013^{\mathrm{e} 6}$ & Expert opinion $^{a}$ & $317 /$ Survey/ $\geq 65$ & 6.0 & \\
\hline \multirow[t]{2}{*}{ Cuba } & Prince et al., $2015^{\mathrm{e}}$ & DSM-IV & $2,944 /$ Urban/ $\geq 65$ & 10.8 & 12.6 \\
\hline & $\begin{array}{l}\text { Llibre Rodriguez et al., 2005, reported by Nitrini et al., 2009, }{ }^{\mathrm{e}} \\
\text { also in Llibre Rodriguez et al., } 2008^{\mathrm{e} 8}\end{array}$ & DSM-IV & $\begin{array}{l}18,351 / \text { Census and medical } \\
\text { registries/ } \geq 65\end{array}$ & 8.2 & 6.5 \\
\hline $\begin{array}{l}\text { Dominican } \\
\text { Republic }\end{array}$ & Prince et al., $2015^{\mathrm{e} 7}$ & DSM-IV & $2,011 /$ Urban/ $\geq 65$ & 11.7 & 9.8 \\
\hline Mexico & Prince et al., $2015^{\mathrm{e} 7}$ & DSM-IV & $1,002 /$ Urban $/ \geq 65$ & 8.6 & 7.4 \\
\hline \multirow[t]{2}{*}{ Peru } & Custodio et al., 2007, reported by Nitrini et al., $2009^{\mathrm{e} 4}$ & DSM-IV & 1,532/Random/>65 & 6.72 & 6.7 \\
\hline & Prince et al., $2015^{\mathrm{e}}$ & DSM-IV & $1,381 /$ Urban/ $\geq 65$ & 9.3 & 8.5 \\
\hline Uruguay & Ketzoian et al., 1997, reported by Nitrini et al., $2009^{\mathrm{e}} 4$ & Expert opinion $^{a}$ & $2,731 /$ Census $/ \geq 65$ & 3.1 & 2.7 \\
\hline \multirow[t]{2}{*}{ Venezuela } & Prince et al., $2015^{\mathrm{e}}$ & DSM-IV & $1,904 /$ Urban/ $\geq 65$ & 5.7 & 6.2 \\
\hline & Maestre et al., 2002, reported by Nitrini et al., $2009^{\mathrm{e}}$ & DSM-IV & $\begin{array}{l}\text { 1,360/Door-to-door survey/ } \\
\geq 65\end{array}$ & 13.7 & 12.2 \\
\hline
\end{tabular}

Abbreviations: DSM-III-R = Diagnostic and Statistical Manual of Mental Disorders, 3rd edition, revised; DSM-IV = Diagnostic and Statistical Manual of Mental Disorders, 4th edition; ICD-10 = International Classification of Diseases-10; Stand = Standardized.

Epidemiologic studies reporting on the prevalence and incidence of dementia in LAC are still needed. Several existing reports have been published in nonindexed Spanish journals, which are often not consulted when generating global statistics. Moreover, some LAC regions such as the Caribbean are underrepresented (e.g., only Cuba and Dominican Republic have conducted epidemiologic studies). The high variability across reports, the low sample size, and the underrepresentation of many countries calls for more rigorous and systematic epidemiologic studies. The table summarizes existing epidemiologic findings in LAC, which reported dementia prevalence.

${ }^{\text {a }}$ No consensus criteria reported. Note that in several LAC we were unable to find enough evidence to include these countries in the table (see e-references, links.IwW.com/WNL/A188).

\section{Access to diagnosis}

Health facilities in LAC are predominantly located in large cities, with a shortage of specialists in small towns and rural areas. In Mexico, only 34\% of the rural dementia population receives support from the government ${ }^{16}$ and dementia health care services are available to very few people. ${ }^{27}$ Moreover, in most LAC, specialized services are covered by private health insurance only. There are no primary health care programs to address diagnosis or timely and adequate referral, and no information is available about the process of referral, when dementia is suspected. At the secondary health level, memory clinics are very rare, although a few LAC provide dementia diagnosis via dedicated research facilities.

\section{Consensus criteria}

In LAC, a limited number of private and public memory clinics located in large cities provide services that meet international consensus criteria and standards. The acceptance of international recommendations on dementia by local scientific/clinical/academic communities is increasing, but does not receive systematic support from relevant stakeholders. Such recommendations provide a framework for the harmonization of diagnostic procedures, to identify individuals transitioning to clinical $\mathrm{AD}{ }^{6}$ Table 1 summarizes how current procedures in LAC map onto these recommendations. Note that in LAC, adoption of these recommendations is restricted to a few centers and does not represent the typical scenario. Although efforts are being made to adhere to such procedures, they are far from homogenous. Interestingly, the use of neuroimaging markers (e.g., amyloid/tau-PET and FDG-PET) appears to be more consistent across LAC than cognitive assessment procedures. Despite neuroimaging evidence heavily emphasized in current international dementia recommendations, ${ }^{6}$ it is not clear how feasible these practices are in LAC (see "Procedures followed to make a diagnosis"). 


\section{Training}

There is an urgent need for training across different levels of the health care system, particularly at the primary care level. Limited training and low confidence of physicians contributes to dementia underdiagnosis/misdiagnosis. ${ }^{28}$ A large proportion of physicians in LAC have not received training regarding differential diagnosis and have limited knowledge about the different forms of dementia. ${ }^{28}$ Some training is offered through relevant national societies, and some training programs are available, but only for neurologists, geriatricians, and psychiatrists. The general scenario demonstrates an urgent need to incorporate education about dementia diagnosis and management from undergraduate and postgraduate programs through to continued education programs for health practitioners, researchers, and social care workers.

\section{Procedures followed to make a diagnosis}

Most LAC follow a basic 3-step clinical algorithm that comprises screening, diagnosis, and classification (i.e., dementia subtypes). Diagnosis is primarily based on clinical information and detailed cognitive assessments are primarily available in private institutions only (table 1). Availability of imaging and biomarkers is restricted to a few centers. For instance, in Argentina, a few institutions have incorporated $\mathrm{AD}$ biomarkers as part of international protocols (e.g., the Alzheimer's Disease Neuroimaging Initiative). Genetic screening is rare with some exceptions (i.e., Colombia and Argentina, not at a national level, but focused on a few centers). The Neuroscience Group of Antioquia has implemented a genetic interview to investigate family inheritance of neurologic diseases. This approach has been key to revealing an unprecedented geographic clustering of neurodegenerative genetic diseases in that country.
Basic recommendations and guidelines for dementia diagnosis are available in a subset of LAC only (e.g., Chile, Argentina, Mexico, and Brazil). ${ }^{16,27}$ In Chile, the Ministry of Health launched guidelines for primary care and a Chilean Society has launched guidelines for specialists. In Argentina, the first Clinical Practice Guidelines have been reported, while the Brazilian Academy of Neurology has made recommendations on diagnostic criteria, screening, neuropsychological evaluation, blood tests, and neuroimaging. However, a much broader health approach as recently launched in $\mathrm{HIC}^{16}$ is required. Thus, although there is local awareness in some countries regarding the importance of harmonizing diagnostic procedures, this awareness has not reached a regional level (i.e., LAC). Moreover, multiple factors such as resources, culture, language, and stigmas affect the accurate diagnosis (table 4).

\section{Therapeutic approaches}

Experience running international or local clinical trials in LAC is mixed. A small amount of drug trials reported worldwide have included LAC, with differences among countries. This region offers an appealing environment for dementia research, although more regional integration is required (table 4). The regional experience lacks systematic organization and regional registries. In some cases, strong bias and negative stereotypes about medication have been observed.

\section{Local regulations}

An important factor limiting participation of LAC in international clinical trials is the position of relevant ethics committees, which until recently have had strong reservations about clinical trials in developing countries, even when they are part of international initiatives. However, there are

Table 4 Regional experience ${ }^{a}$

\begin{tabular}{ll}
\hline Clinical trials & Of the 715 intervention studies reported worldwide, only 51 included LAC (Chile: 20, Argentina: 17, Brazil: 8, Peru: 4, Colombia: 1, \\
& and Venezuela: 1). ${ }^{\text {e9-10 }}$ Moreover, of the 363 current AD drug trials, only 2 involved LAC. Trials of gantenerumab in prodromal AD \\
& are underway in Brazil, Argentina, and Chile. Trials of solanezumab in AD are ongoing in Brazil and Argentina. In Peru, in the last 2 \\
& years, trials of masitinib and gantenerumab have been rejected by the National Health Institute. In contrast, the Neuroscience \\
& Group from Antioquia, Colombia, is currently running one of the largest prevention trials involving asymptomatic PSEN1 gene \\
& mutation carriers (API Colombia program ${ }^{\text {10 }}$ ).
\end{tabular}

Unique conditions

LAC offer a unique and appealing environment for drug research, given the combination of large populations living in large cities together with the presence of rare conditions such as clusters of autosomal dominant variants of neurodegenerative diseases causing $A D$, vascular dementia, frontotemporal dementia, and Huntington disease. ${ }^{\text {e9-12 }}$ Such population characteristics enable accelerated enrollment, high recruitment levels, high retention rates, and simplified follow-up algorithms. These factors can dramatically improve trial efficiency, adherence to tight timelines, and resource optimization.

Absent regional

regulation
The lack of regional registries for clinical trials poses important restrictions for LAC. No systematic information regarding the effect of clinical trials on highly vulnerable populations exists (e.g., exposed to poverty, violence, low education, and other types of social deprivation). Moreover, some dementia subtypes are underinvestigated (e.g., Huntington disease, cerebral autosomal dominant arteriopathy with subcortical infarcts and leukoencephalopathy, and Parkinson disease). 
encouraging examples in the region, including a landmark prevention trial in familial $\mathrm{AD}$ in Columbia. ${ }^{7,29}$ Some $\mathrm{LAC}$ have government regulations that pose challenges to clinical trials. For instance, in Chile, a new law on patients' rights and duties imposes several restrictions. Article 23 of the law 20584 prohibits the participation of vulnerable people in scientific research studies who are unable to provide consent. This has caused concerns among ethics committees, which have had to reject applications based on such legislation, affecting researchers as well as people with dementia. Also, most research is supported by industry, with academic trials representing a small proportion of research and involving small sample sizes (although this does not seem to be specific to LAC). The implications of this pattern for the direction of research as well as the validity and availability of results merits attention in future works. Finally, no regional guidelines for multicountry clinical trials exist. Thus, some local regulations may need to be revised to reflect global dementia strategies.

\section{Currently available treatments}

Unlike many HIC (e.g., United Kingdom, France, Norway, United States, and South Korea) where governments have developed specific dementia plans or strategies, most LAC have minimal mental health facilities with no specific policies or budgets for mental health. ${ }^{15}$ Currently available treatments, research opportunities, and clinical assessment of dementia appears to depend on a country's political stability and economic capacity ${ }^{16,30-32}$ (appendix e-1, S6, links.lww.com/ WNL/A97).
In Chile, as in many other LAC, care is mostly delivered by family relatives, with most of the cost of dementia accounted for by informal care. ${ }^{16}$ Availability of pharmaceuticals for dementia across LAC is variable, with the exception of Mexico, where the cost of dementia medications is much lower than in other LMIC. ${ }^{27}$ In Colombia and Peru, only private health insurance companies provide acetylcholinesterase inhibitors (AI) or glutamate modulators. In Chile, the public health system delivers pharmaceutical treatment for neuropsychiatric symptoms of dementia, but does not cover specific treatments for dementia subtypes. The Brazilian government supports treatment with $\mathrm{AI}$ for $\mathrm{AD}$; however, respite facilities or nursing home access are not supported. In Argentina, AI, Souvenaid, and Cerebolysin are supported by the public health system. Moreover, patients with dementia have access to a national certificate of disability, which allows them access to full medical coverage. In general, memory enhancers are difficult to obtain. Moreover, nonpharmacologic treatments, as well as social and health support postdiagnosis, pose similar challenges in LAC (tables 5 and 6).

Nonpharmacologic approaches may offer an attractive alternative for LAC. At the Alzheimer's Association International Conference 2016, evidence on cognitive intervention programs using information technology was presented. Such approaches have shown relevant improvements in cognitive functions, transfer across cognitive domains, and enhanced functioning in randomized controlled trials. Interestingly, these effects appear to persist to some extent for at least 5 years. $^{33}$ More recently, the Finnish Geriatric Intervention Study to Prevent Cognitive Impairment and Disability

Table 5 Factors affecting timely diagnosis ${ }^{a}$

\begin{tabular}{ll}
\hline The private/public & The private/public divide determines the quality and promptness of diagnosis, the length of waiting lists, and the proportion of \\
divide & people who can access health care facilities. Intervention programs in Argentina, Chile, Dominican Republic, Mexico, Peru, and \\
& Venezuela showed larger effects on caregiver psychological morbidity and burden than in HIC. ${ }^{\text {13 }}$ There are no centers of \\
& excellence at a public level. This lack of access, together with socioeconomic inequalities, highlights the importance of identifying \\
& actions that can address these urgent needs. ${ }^{14}$
\end{tabular}

Cultural differences More than 400 different indigenous groups are estimated to live within LAC, ${ }^{\mathrm{e} 15}$ and around $89 \%$ of them live in Bolivia, Guatemala, Peru, Ecuador, and Mexico, which have 5-13 million indigenous citizens each. ${ }^{\mathrm{e} 16}$ In Mexico, $16 \%$ of the population is indigenous and this population is facing major difficulties accessing dementia care. ${ }^{\text {e17 }}$ Moreover, illiteracy and low education are major problems affecting most LAC ${ }^{\mathrm{e} 18-\mathrm{e} 19}$ (the illiteracy rate in the older population is approximately $10 \%{ }^{\mathrm{e} 20}$ ). Even high levels of food insecurity have been observed in the Dominican Republic, Mexico, and Peru ${ }^{\mathrm{e} 13}$ in people with dementia. The extent to which these sociocultural factors influence dementia prevalence in LAC needs to be investigated.

\begin{tabular}{|c|c|}
\hline $\begin{array}{l}\text { Language } \\
\text { differences }\end{array}$ & $\begin{array}{l}\text { LAC are not homogenous in terms of language (e.g., ethnic minorities and indigenous groups with specific communication } \\
\text { systems). Several countries have indigenous populations who speak non-Spanish native languages. Most tests used for the } \\
\text { detection of cognitive impairments have been adapted and translated from different cultural backgrounds. }{ }^{\text {18-e19 }} \text { Thus, there is } \\
\text { a need for culturally unbiased language-free approaches to assess these populations. Although there have been a few attempts to } \\
\text { tackle this issue (see reference e21), the basis of cultural effects is poorly understood. Normative data are likely not generalizable } \\
\text { across different populations }^{\mathrm{e} 22} \text { and can influence dementia misdiagnosis. }{ }^{\text {e23 }}\end{array}$ \\
\hline Stigma & $\begin{array}{l}\text { LAC with more education and improved health facilities have better dementia diagnosis and outcome. }{ }^{e 24} \text { For example, according } \\
\text { to experts from Colombia, families affected by the gene mutation (familial AD) believe the disease is a deterministic, natural } \\
\text { condition and thus do not hope for any solution from the health system. In Chile, negative stigma is observed in members of the } \\
\text { Mapuche community, which has a high prevalence of dementia. In Mexico (as in many other LAC), low levels of awareness } \\
\text { contribute to low rates of diagnosis. }{ }^{17} \text { Some families are reticent to disclose the diagnosis to affected relatives. Indeed, stigma has } \\
\text { been recognized as a major factor preventing the implementation of effective dementia strategies not only in LAC, but around the } \\
\text { world. }{ }^{25} \text { Thus, stigma and myths associated with the diagnosis of dementia are important in LAC and require specific actions. }\end{array}$ \\
\hline
\end{tabular}


Table 6 Social and health support after diagnosis ${ }^{a}$

\begin{tabular}{|c|c|}
\hline Models of care & $\begin{array}{l}\text { Models of care from developed countries may not be suitable to implement in LAC without important modifications, given } \\
\text { socioeconomic and sociocultural differences, especially in LMIC, } 13 \text { where resources are limited. There is a lack of explicit care } \\
\text { schemes in many LAC. }{ }^{17} \text { Although dementia has emerged as the leading single chronic disease contributor to dependence in } \\
\text { people }>65 \text { years in many LAC, }{ }^{\mathrm{e} 6} \text { governments are not yet fully aware of the magnitude of the problem. }\end{array}$ \\
\hline Family support & $\begin{array}{l}\text { Family support remains the main pillar for patients after dementia diagnosis; however, adequate networking between affected } \\
\text { families or with extended social groups is limited. Furthermore, families cannot support the cost of interventions in continuously } \\
\text { changing conditions. }{ }^{27} \text { This represents a serious problem given the reduced survival in individuals embedded in restricted social } \\
\text { networks. }{ }^{\mathrm{e} 28} \text { This problem is further exacerbated in LIC where poverty is common and makes patients particularly vulnerable. } \\
\text { Although care is sometimes divided among several family members, one individual typically provides the majority of care, }{ }^{\text {e13,e29 }} \\
\text { which usually leads to increased carer burden }{ }^{\mathrm{e} 29} \text { (see appendix e-1, S6, links.lww.com/WNL/A97). }\end{array}$ \\
\hline $\begin{array}{l}\text { Additional LAC } \\
\text { constraints }\end{array}$ & $\begin{array}{l}\text { The number of physicians per affected individual is variable between countries, as well as the proportion of private and public } \\
\text { organizations. The distribution of resources is unequal and those less advantaged have very little or no social support (with Cuba } \\
\text { as an exception }{ }^{-13} \text { ). In most LAC, there are no national social programs, but private, academic, religious, philanthropic, and } \\
\text { industry-based local programs exist. }{ }^{-13,17} \text { Aware of this challenge, some LAC have started to implement initiatives to support } \\
\text { affected families; for example, ALMA in Argentina, "No me olvides" in Colombia, CIAM in Peru, and the Brazilian Federation of } \\
\text { Alzheimer's Associations. Such initiatives could be strengthened and expanded by incorporating IT platforms such as } \\
\text { telemedicine (e.g., Venezuela telemedicine program). Issues such as lack of Internet access or electricity in most of the rural } \\
\text { regions of LAC, however, will need to be addressed first }{ }^{\mathrm{e} 27} \text { (see also appendix e-1, S6, links.lww.com/WNL/A97). }\end{array}$ \\
\hline
\end{tabular}

Abbreviations: $\mathrm{LAC}=$ Latin American countries; LIC = low-income countries

a See e-references, links.IwW.com/WNL/A188.

(FINGER) study has combined comprehensive intervention with technology to enhance cognitive functions. ${ }^{34}$ The use of technology has become common practice among older people from LAC. Some researchers have started to investigate whether this social trend could offer new opportunities to assess functioning in those at risk of dementia. ${ }^{35}$ Nevertheless, we acknowledge that though promising, this area is in its infancy and more work will be needed before it can be introduced into clinical practice.

\section{Potential avenues for collaboration}

Even at a global level, comprehensive dementia health care cannot be afforded by existing care models. ${ }^{27}$ The potential of LAC to tackle important priorities in dementia research is unanimously acknowledged by this expert panel.

\section{Promoting collaboration forums and large-scale computational capacity}

One option for LAC is to establish an agenda to organize meetings in different countries, which could create opportunities for researchers to discuss local work and increase scientific debate and interactions (appendix e-1, S4, links.lww. com/WNL/A97). Secondly, the development of large-scale computational capacity (e.g., Linux clusters) would offer a platform for intensive dementia research, screening programs, and big data analysis (appendix e-1, S4).

\section{Capitalizing on unique populations}

LAC offer access to unique populations (genetic clusters, low literacy, multilingual, multiethnic). ${ }^{36}$ This region hosts the world's largest populations of familial $\mathrm{AD}$ (Colombia), Huntington disease (Venezuela), and ataxia (Cuba), alongside multiple novel and rare functional genomic variants of other diseases. For instance, the Caribbean has a high late-onset dementia incidence, and genetic studies have shown large effect sizes. ${ }^{37}$ These unique genetic presentations can be exploited at a regional level. Moreover, the socioeconomic status of several communities provides a natural scenario to study the role of vulnerability, resilience, and gene-environment interactions, such as in the blue zones. Multilingualism is another important factor that can be studied. Many LAC are suitable for studying bilingualism and its influence on cognitive reserve in situ. In LAC, it is possible to find people who are illiterate, but still functioning at a relatively normal level within their community. In Mexico, Peru, Cuba, and Dominican Republic, education and literacy seems to protect against dementia onset. ${ }^{20}$ Studying these populations may help to disentangle the effects of education and other social factors. Finally, the development of robust cognitive neuroscience methods to tackle dementia research are now emerging in the region. ${ }^{38-51}$ However, the need for more research at a global level is necessary ${ }^{27}$ and LAC should be integrated into this pathway.

The unique conditions found in LAC could inform causal inference by etiologic triangulation. ${ }^{52}$ This triangulation from different approaches and measures can unveil key sources of potential bias. Combining different regional approaches (within LAC and among LAC and other regions) with studies at different levels (genetic, cognitive, neuronal, epidemiologic), which are available to researchers globally at a modest cost, will represent a novel advance in the field of dementia.

\section{Toward a regional network for translation research}

Several LAC are currently working with animal models. Examples include the Neuroscience Group of Antioquia, 
Colombia; the Federal University of Rio de Janeiro, Brazil; the Max Planck Institute and the Institute of Cognitive and Translational Neuroscience in Argentina; the Geroscience Center for Brain Health and Metabolism; and the Fraunhofer Institute from Chile. Advances are being made by studying species such as the Octodon degus, an endemic rodent from Chile that spontaneously develops an analogue of dementia. ${ }^{53}$ The use of low-cost accessible technologies such as inexpensive cognitive screening tools that are culturally unbiased ${ }^{54}$ as well as additional measures such as high-density, portable, and even basic $\mathrm{EEG}^{40,45,55,56}$ may provide affordable improved assessment solutions in the short term. Standardization of collection and measurement is necessary to take advantage of clinical developments, imaging, biomarkers, and clinical trials. ${ }^{12}$ It is time to do this at the LAC network level.

\section{Discussion}

The key aim of this article was to identify areas of priority on which LAC should focus, to join global research on dementia, and to harmonize clinical and research practices internationally. We have provided evidence indicating that such harmonization may need to be preceded by regional solutions to address the most imminent priorities (appendix e-1, S5, links.lww.com/WNL/A97).

We have identified regional gaps and strategies. Core gaps include (1) limited reliable epidemiologic data, (2) lack of a LAC dementia strategy encouraging governments to set specific mental health policies and budgets, (3) lack of culturally valid assessment procedures and reliable diagnostic markers that enable comparison of dementia figures among LAC and internationally, and (4) lack of a unified LAC agenda to facilitate collaboration and rapid translation of research findings in the region (tables 2 and 3 for details). Strategies to tackle these regional needs were also identified. These include (1) dissemination aimed at increasing outputs in scientific outlets, educational materials, and social media; (2) an integration agenda aimed at increasing opportunities for scientific debate and interactions, professional training, knowledge and resource exchanges, and shared IT infrastructure; and (3) a political agenda targeting relevant stakeholders, policy makers, government agencies, and international organizations to raise awareness of LAC challenges and support harmonization of strategies globally (table 2). Several unresolved issues will require joint efforts between LAC. Certainly, this is not a comprehensive treatment of all relevant issues. For instance, prevention and prevention research are important topics outside the scope of the article that should be assessed in future works. It is not entirely clear whether and how models of diagnosis and care from developed countries can be implemented, at least at present, in LAC. Given socioeconomic and sociocultural differences, we anticipate that critical modifications will be necessary.
For instance, all these topics presented above could trigger immediate actions:

- There is a need for scientifically rigorous regional epidemiologic studies that systematically investigate prevalence, incidence, resilience, and cognitive reserve.

- $\quad$ LAC need a national and a regional dementia strategy. Such strategy should be aimed at heads of governments and international agencies to encourage more regional collaboration.

- Support will be needed from national/international organizations to enable a smooth and timely transition of LAC from their current status to a position that best captures global strategies.

- More collaboration between LAC is urgently needed, including (1) promoting new regional collaboration forums; (2) capitalizing on unique populations; (3) working toward a regional network for translational research and assessment; and (4) developing LAC dementia registries to accelerate research discoveries.

We envisage that this opinion article will pave the way toward a LAC working agenda that will harness the support needed both to provide better care for people with dementia and to facilitate the translation of research developments into local solutions that meet global standards.

\section{Author contributions}

A.I. and M.A.P. designed the proposal. M.A.P., S.B., and A.I. wrote the first draft, discussed contributions from all coauthors, and approved the final version. M.A.P., A.I., and S.B. prepared the tables. All authors searched the literature, participated in discussing the contents of the paper, contributed to editing, and approved the final version of the article.

\section{Study funding}

The Expert Meeting was supported by Alzheimer's Society UK grants awarded to M.A.P. in collaboration with A.I. (ASR42303, AS-SF-14-008). The Article Processing Charge was funded by CONICYT-Fondecyt Regular N¹170010.

\section{Disclosure}

M. Parra, S. Baez, R. Allegri, and R. Nitrini report no disclosures relevant to the manuscript. F. Lopera is supported by a grant API COLOMBIA funded by GENENTECH and Banner Institute. A. Slachevsky is supported by CONICYT/ FONDAP / 15150012, Conicyt/Fondecyt Regular/1140423, and Basal Funds for Centers of Excellence, Project FB 0003 from the Associative Research Program of CONICYT. N. Custodio and D. Lira report no disclosures relevant to the manuscript. O. Piguet is supported by an NHMRC Senior Research Fellowship (APP1103258); support from $\mathrm{Alz}$ heimer's Scotland Dementia Research and the Centre for Cognitive Ageing and Cognitive Epidemiology part of the cross-council Lifelong Health and Wellbeing Initiative (MR/ K026992/1), both from the University of Edinburgh, is also 
acknowledged. F. Kumfor is supported by a National Health and Medical Research Council of Australia (NHMRC)Australian Research Council Dementia Research Development Fellowship (APP1097026). D. Huepe, P. Cogram, T. Bak, and F. Manes report no disclosures relevant to the manuscript. A. Ibanez is partially supported by grants from CONICET, CONICYT/FONDECYT Regular (1170010), FONCyT-PICT 2012-0412, FONCyT-PICT 2012-1309, FONDAP 15150012, INECO Foundation, and the InterAmerican Development Bank. Go to Neurology.org/N for full disclosures.

Received July 29, 2017. Accepted in final form October 2, 2017.

\section{References}

1. Shah H, Albanese E, Duggan C, et al. Research priorities to reduce the global burden of dementia by 2025. Lancet Neurol 2016;15:1285-1294.

2. A neurology revival in Latin America. Lancet Neurol 2015;14:1143.

3. Alzheimer's Disease International. World Alzheimer Report: Executive Summary. London: Alzheimer's Disease International;2009.

4. Manes F. The huge burden of dementia in Latin America. Lancet Neurol 2016;15: 29.

5. Kalaria RN, Maestre GE, Arizaga R, et al. Alzheimer's disease and vascular dementia in developing countries: prevalence, management, and risk factors. Lancet Neurol 2008; 7:812-826.

6. Dubois B, Hampel H, Feldman HH, et al. Preclinical Alzheimer's disease: definition, natural history, and diagnostic criteria. Alzheimers Dement 2016;12:292-323.

7. Reiman EM, Langbaum JB, Fleisher AS, et al. Alzheimer's prevention initiative: a plan to accelerate the evaluation of presymptomatic treatments. J Alzheimer's Dis 2011;26 (suppl 3):321-329.

8. Sperling RA, Karlawish J, Johnson KA. Preclinical Alzheimer disease: the challenges ahead. Nat Rev Neurol 2013;9:54-58.

9. Fox CJ, Lafortune L, Boustani M, Brayne C. The pros and cons of early diagnosis in dementia. Br J Gen Pract 2013;63:e510-e512.

10. Brayne C, Fox CJ, Boustani M. Dementia screening in primary care: is it time? JAMA 2007;298:2409-2411.

11. Cece Y, Shifu X. Are the revised diagnostic criteria for Alzheimer's disease useful in low- and middle-income countries? Shanghai Arch Psychiatry 2015;27:119-123.

12. Scheltens P, Blennow K, Breteler MM, et al. Alzheimer's disease. Lancet 2016;388: 505-517.

13. Prince MJ, Wimo A, Guerchet MM, Ali GC, Wu YT, Prina M. World Alzheimer Report 2015: The Global Impact of Dementia.London: Alzheimer's Disease International;2015.

14. Alzheimer's Disease International. World Alzheimer Report 2015. The Global impact of dementia: an analysis of prevalence, incidence, cost \& trends. World Alzheimer Report 2015. Available at: alz.co.uk/research/world-report-2015. Accessed 2016.

15. Prince M, Bryce R, Albanese E, Wimo A, Ribeiro W, Ferri CP. The global prevalence of dementia: a systematic review and metaanalysis. Alzheimers Dement 2013;9; 63-75.

16. World Health Organization and Alzheimer's Disease International. Dementia: A Public Health Priority. Geneva: World Health Organization; 2012.

17. Jackson RL, Aparici G, Nakashima K, Strauss R, Howe N. Latin America's Aging Challenge: Demographics and Retirement Policy in Brazil, Chile, and Mexico. Washington, DC: Center for Strategic and International Studies; 2009.

18. Sosa AL, Albanese E, Stephan BC, et al. Prevalence, distribution, and impact of mild cognitive impairment in Latin America, China, and India: a 10/66 population-based study. PLoS Med 2012;9:e1001170.

19. Llibre Rodriguez JJ, Ferri CP, Acosta D, et al. Prevalence of dementia in Latin America, India, and China: a population-based cross-sectional survey. Lancet 2008; 372:464-474.

20. Prince M, Acosta D, Ferri CP, et al. Dementia incidence and mortality in middleincome countries, and associations with indicators of cognitive reserve: a 10/66 Dementia Research Group population-based cohort study. Lancet 2012;380:50-58.

21. Ferri CP, Prince M, Brayne C, et al. Global prevalence of dementia: a Delphi consensus study. Lancet 2005;366:2112-2117.

22. Mehta KM, Yeo GW. Systematic review of dementia prevalence and incidence in US race/ethnic populations. Alzheimers Dement 2016;13:72-83.

23. Ramos-Cerqueira AT, Torres AR, Crepaldi AL, et al. Identification of dementia cases in the community: a Brazilian experience. J Am Geriatr Soc 2005;53:1738-1742.

24. Maestre GE, Pino-Ramirez G, Molero AE, et al. The Maracaibo Aging Study: population and methodological issues. Neuroepidemiology 2002;21:194-201.

25. Lobo A, Launer LJ, Fratiglioni L, et al. Prevalence of dementia and major subtypes in Europe: a collaborative study of population-based cohorts: Neurologic Diseases in the Elderly Research Group. Neurology 2000;54:S4-S9.
26. Sousa RM, Ferri CP, Acosta D, et al. Contribution of chronic diseases to disability in elderly people in countries with low and middle incomes: a 10/66 Dementia Research Group population-based survey. Lancet 2009;374:1821-1830.

27. Prince M, Comas-Herrera A, Knapp M, Guerchet M, Karagiannidou M. World Alzheimer Report 2016: Improving Healthcare for People Living With Dementia: Coverage, Quality and Costs Now and in the Future. London: Alzheimer's Disease International; 2016

28. Gleichgerrcht E, Flichtentrei D, Manes F. How much do physicians in Latin America know about behavioral variant frontotemporal dementia? J Mol Neurosci 2011;45: $609-617$.

29. Quiroz YT, Lopera F, Budson AE. Charting the path for early diagnosis and prevention of Alzheimer's disease. Expert Rev Neurother 2011;11:1665-1667.

30. Gonzalez FJ, Gaona C, Quintero M, Chavez CA, Selga J, Maestre GE. Building capacity for dementia care in Latin America and the Caribbean. Dement Neuropsychol 2014;8:310-316.

31. Ottersen OP, Dasgupta J, Blouin C, et al. The political origins of health inequity: prospects for change. Lancet 2014;383:630-667.

32. Savedoff WD, de Ferranti D, Smith AL, Fan V. Political and economic aspects of the transition to universal health coverage. Lancet 2012;380:924-932.

33. Tennstedt SL, Unverzagt FW. The ACTIVE study: study overview and major findings. J Aging Health 2013;25:3S-20S.

34. Ngandu T, Lehtisalo J, Solomon A, et al. A 2 year multidomain intervention of diet, exercise, cognitive training, and vascular risk monitoring versus control to prevent cognitive decline in at-risk elderly people (FINGER): a randomised controlled trial. Lancet 2015;385:2255-2263.

35. Munoz-Neira C, Lopez OL, Riveros R, Nunez-Huasaf J, Flores P, Slachevsky A. The technology-activities of daily living questionnaire: a version with a technology-related subscale. Dement Geriatr Cogn Disord 2012;33:361-371.

36. Baez S, Ibanez A. Dementia in Latin America: an emergent silent tsunami. Front Aging Neurosci 2016;8:253

37. Reitz C, Mayeux R. Genetics of Alzheimer's disease in Caribbean Hispanic and African American populations. Biol Psychiatry 2014;75:534-541.

38. Sedeno L, Piguet O, Abrevaya S, et al. Tackling variability: a multicenter study to provide a gold-standard network approach for frontotemporal dementia. Hum Brain Mapp 2017;38:3804-3822.

39. Garcia AM, Abrevaya S, Kozono G, et al. The cerebellum and embodied semantics: evidence from a case of genetic ataxia due to STUB1 mutations. J Med Genet 2017;54: 114-124.

40. Dottori M, Sedeno L, Martorell Caro M, et al. Towards affordable biomarkers of frontotemporal dementia: a classification study via network's information sharing. Sci Rep 2017;7:3822.

41. Abrevaya S, Sedeno L, Fitipaldi S, et al. The road less traveled: alternative pathways for action-verb processing in Parkinson's disease. J Alzheimer's Dis 2017;55 1429-1435.

42. Sedeño L, Couto B, García-Cordero I, et al. Brain network organization and social executive performance in frontotemporal dementia. J Int Neuropsychol Soc 2016;22: 250-262.

43. Melloni M, Billeke P, Baez S, et al. Your perspective and my benefit: multiple lesion models of self-other integration strategies during social bargaining. Brain 2016;139: 3022-3040.

44. García-Cordero I, Sedeño L, de la Fuente L, et al. Feeling, learning from, and being aware of inner states: interoceptive dimensions in neurodegeneration and stroke. Philos Trans R Soc Lond B Bio Sci 2016;371:20160006.

45. Melloni M, Sedeno L, Hesse E, et al. Cortical dynamics and subcortical signatures of motor-language coupling in Parkinson's disease. Sci Rep 2015;5:11899.

46. Ibanez A, Manes F. Contextual social cognition and the behavioral variant of frontotemporal dementia. Neurology 2012;78:1354-1362.

47. Pietto M, Parra MA, Trujillo N, et al. Behavioral and electrophysiological correlates of memory binding deficits in patients at different risk levels for Alzheimer's disease. J Alzheimers Dis 2016;53:1325-1340.

48. Parra MA, Saarimaki H, Bastin ME, et al. Memory binding and white matter integrity in familial Alzheimer's disease. Brain 2015;138:1355-1369.

49. Parra MA, Abrahams S, Logie RH, Mendez LG, Lopera F, Della Sala S. Visual short-term memory binding deficits in familial Alzheimer's disease. Brain 2010;133:2702-2713.

50. Garcia-Cordero I, Sedeno L, Fraiman D, et al. Stroke and neurodegeneration induce different connectivity aberrations in the insula. Stroke 2015;46:2673-2677.

51. Baez S, Pino M, Berrio M, et al. Corticostriatal signatures of schadenfreude: evidence from Huntington's disease. J Neurol Neurosurg Psychiatry 2018;89:112-116.

52. Lawlor DA, Tilling K, Davey Smith G. Triangulation in aetiological epidemiology. Int J Epidemiol 2016;45:1866-1886.

53. Ardiles AO, Tapia-Rojas CC, Mandal M, et al. Postsynaptic dysfunction is associated with spatial and object recognition memory loss in a natural model of Alzheimer's disease. Proc Natl Acad Sci USA 2012;109:13835-13840.

54. Parra M. Overcoming barriers in cognitive assessment of Alzheimer's disease. Dement Neuropsychol 2014;8:95-98.

55. Ibanez A, Parra MA. Mapping memory binding onto the connectome's temporal dynamics: toward a combined biomarker for Alzheimer's disease. Front Hum Neurosci 2014;8:237.

56. Scally B, Calderon P, Anghinah R, Parra M. Event-related potentials in the continuum of Alzheimer's disease: would they suit recent guidelines for preclinical assessment? J Clin Diagn Res 2016;4. 


\section{Neurology}

\section{Dementia in Latin America: Assessing the present and envisioning the future}

Mario A. Parra, Sandra Baez, Ricardo Allegri, et al.

Neurology 2018;90;222-231 Published Online before print January 5, 2018

DOI 10.1212/WNL.0000000000004897

This information is current as of January 5, 2018

\section{Updated Information \& Services}

References

Citations

Subspecialty Collections

\section{Permissions \& Licensing}

Reprints including high resolution figures, can be found at: http://n.neurology.org/content/90/5/222.full

This article cites 48 articles, 6 of which you can access for free at: http://n.neurology.org/content/90/5/222.full\#ref-list-1

This article has been cited by 1 HighWire-hosted articles: http://n.neurology.org/content/90/5/222.full\#\#otherarticles

This article, along with others on similar topics, appears in the following collection(s):

All Cognitive Disorders/Dementia

http://n.neurology.org/cgi/collection/all_cognitive_disorders_dementia All Practice Management

http://n.neurology.org/cgi/collection/all_practice_management Assessment of cognitive disorders/dementia

http://n.neurology.org/cgi/collection/assessment_of_cognitive_disorder s_dementia

Diagnostic test assessment

http://n.neurology.org/cgi/collection/diagnostic_test_assessment_

Information about reproducing this article in parts (figures,tables) or in its entirety can be found online at:

http://www.neurology.org/about/about_the_journal\#permissions

Information about ordering reprints can be found online:

http://n.neurology.org/subscribers/advertise

Neurology ${ }^{\circledR}$ is the official journal of the American Academy of Neurology. Published continuously since 1951, it is now a weekly with 48 issues per year. Copyright @ 2018 The Author(s). Published by Wolters Kluwer Health, Inc. on behalf of the American Academy of Neurology.. All rights reserved. Print ISSN: 0028-3878. Online ISSN: 1526-632X.

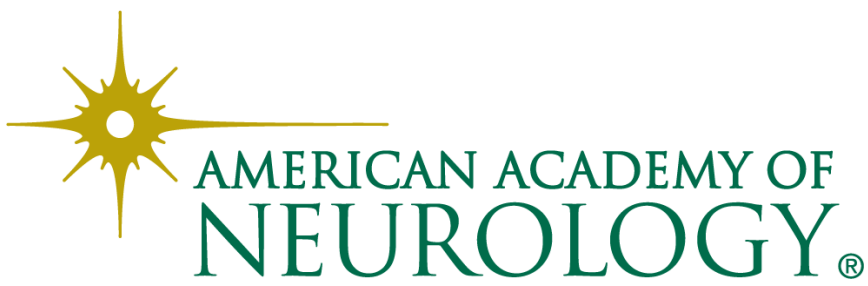

